\title{
New sustained release of Zidovudine Matrix tablets - cytotoxicity toward Caco-2 ells
}

\author{
Jucimary V. Santos ${ }^{1,2}$, Maria Eugénia T. Pina ${ }^{2}$, M. Paula M. Marques ${ }^{1,3}$, and \\ Luís A. E. Batista de Carvalho ${ }^{1}$ \\ ${ }^{1}$ Unidade de I\&D “Química-Física Molecular", Department of Chemistry, Faculty of Science and Technology, \\ University of Coimbra, Coimbra, Portugal, ${ }^{2}$ Centro de Estudos Farmacêuticos (CEF), Pharmaceutical Technology \\ Laboratory, Faculty of Pharmacy, University of Coimbra, Coimbra, Portugal, and ${ }^{3}$ Department of Life Sciences, \\ Faculty of Science and Technology, University of Coimbra, Portugal
}

\begin{abstract}
Objective: The aim of this study was to adjust the zidovudine (AZT) release from solid tablets to an ideal profile, by developing matrices comprising swellable polymers with nonswellable ones.

Methods: Directly compressed matrices comprised different ratios of hydroxypropylmethylcellulose K15M and K100M, ethylcellulose, and methacrylic acid (Eudragit ${ }^{\circledR}$ RS PO and Eudragit $\AA$ RL PO) were prepared. Technological characterization and evaluation of the in vitro release behavior were carried out. Cell density and viability following drug exposure were evaluated by the SRB method, for the Caco-2 line, while cell morphology was assessed upon Trypan blue staining.

Results: A specific formulation containing $5 \%$ of each excipient - HPMC K15M, HPMC K100M, Eudragit ${ }^{\circledR}$ RS PO, and Eudragit ${ }^{\circledR}$ RL PO - was found to yield the best release profile. Application of the Korsmeyer-Peppas model to the dissolution profile evidenced that a non-Fickian (anomalous) transport is involved in the drug release. Regarding the influence of the tablets' composition on the drug's cytotoxic effect toward the Caco- 2 cell line, a reduction of cell biomass (0-15\%) was verified for the distinct AZT formulations tested, F19 having displayed the highest cytotoxicity, after 24 and $48 \mathrm{~h}$ of incubation. Additionally, a high reversibility of the AZT effect was observed.

Conclusions: The results showed that the simultaneous application of both hydrophilic and hydrophobic polymers can modulate the drug release process, leading to an improved efficacy and patient compliance. All AZT formulations studied were found to be cytotoxic against Caco-2 cells, F19 being the most effective one.
\end{abstract}

Keywords: Zidovudine (AZT), hydroxypropylmethylcellulose (HPMC), Eudragit ${ }^{\circledR}$, in vitro release, antiproliferative effect, Raman spectroscopy

\section{Introduction}

Zidovudine (3'-azido-3'deoxythimidine, azydothymidine, AZT, 1-[(2R, 4S, 5S)-4-azido-5-(hydroxymethyl) oxolan-2yl]-5-methyl-pyrimidine-2, 4-dione) is a thymidine analog that inhibits the replication of the human immunodeficiency virus. It was the first approved anti-HIV drug ${ }^{1}$ and has been used for the treatment of AIDS, since the late 1980s. However, AZT therapy using conventional formulations is frequently associated with dose-dependent adverse reactions, mainly anemia and neutropenia ${ }^{2,3}$.
Zidovudine is known to be rapidly absorbed from the gastrointestinal tract, presenting a presystemic biotransformation and an oral bioavailability of $c a .63 \%{ }^{4,5}$. Since AZT has a short plasma elimination half life $(\sim 1 \mathrm{~h})^{4,5}$, quite large dosages are required to sustain its therapeutic level. When orally administered, these cause considerable damage at the gastrointestinal level. Furthermore, since zidovudine's antiviral activity is time-dependent, an adequate zero-order delivery of AZT is required for preserving anti-HIV action and minimizing the side effects.

Address for Correspondence: Unidade de I\&D “Química-Física Molecular”, Departamento de Química, Faculdade de Ciências e Tecnologia, Universidade de Coimbra, Rua Larga, 3004-535 Coimbra, Portugal. Tel: +351-239-854462. Fax: +351-239-826541. E-mail: labc@ci.uc.pt 
The bioavailability of a particular drug, as well as its pharmacokinetics and pharmacodynamics, is strongly dependent on the dosage form used. A thorough understanding of the phenomena taking place upon exposure of a given body to a certain pharmacological agent is thus essential for the development of improved controlled release drug formulations. Sustained drug delivery systems are designed to achieve a continuous release of a pharmaceutical agent at a predictable and reproducible kinetics, over an extended period of time, with a consequent minimization of drug-related deleterious side effects and improved patient compliance, which is greater in the case of oral formulations ${ }^{6-9}$.

Since the newly established protocol ruling toxicological tests ${ }^{10,11}$ severely limits the use of animals in lethal experiments, there has been an increased interest in in vitro techniques, for obtaining reliable biological data ${ }^{12,13}$. The human cell line Caco-2, in particular, has shown to be a suitable and reliable model for this kind of studies ${ }^{14}$, as it is derived from human colon adenocarcinoma cells and exhibits several classes of different markers typically found in adult's intestinal differentiated cells (e.g., alkaline phosphatase and microvilli in the brush border $)^{15-19}$. In fact, the use of Caco-2 cells in cytotoxicity evaluation experiments presents several advantages: (i) there are no significant differences in either the morphological or physiological characteristics of intestinal cancer cells compared to normal cells ${ }^{15,20}$; (ii) it allows to gather information on the potential drug's toxicity toward the mucosa ${ }^{21-23}$; (iii) it provides information, at the cellular level, on drug's absorption, metabolism, and transport through the intestinal wall ${ }^{24-29}$.

Despite the several studies reported to date on AZT sustained release formulations, seeking an optimized therapy for HIV/AIDS ${ }^{30-41}$, no reports have been found on their prospective clinical application. However, the severity of HIV and its related disorders urges for reliable strategies on oral sustained release formulations, particularly regarding AZT. The present work aims at contributing to this goal, of the utmost relevance for human health, by assessing the suitability of several hydrophilic and hydrophobic polymer mixtures. A novel approach is presented for the promotion of the drug's gastrointestinal absorption, increasing its bioavailability at a therapeutically adequate rate and leading to a higher therapeutic efficiency coupled to a lower toxicity. For those formulations, yielding the best drug release behavior, the antiproliferative and cytotoxic properties against Caco- 2 cells were also evaluated.

\section{Methods}

\section{Materials}

Drug: Zidovudine (lot. $\mathrm{n}^{\circ}$ 061218) was purchased from CIPLA, India. Polymers: Eudragit ${ }^{\circledR}$ RS PO (lot. ${ }^{\circ}$ 0400938137) and Eudragit ${ }^{\circledR}$ RL PO (lot. $n^{\circ}$ 0410836093) Röhm Pharma - Germany; Ethylcellulose 48.9\% lot. $\mathrm{n}^{\circ}$ 036k0185, Sigma-Aldrich- Germany, USA;
Hydroxypropylmethylcellulose, Methocel ${ }^{\circledR}$ K15M lot $\mathrm{n}^{\circ}$ OG20012N31 and Methocel® K100M lot ${ }^{\circ}{ }^{\circ} \mathrm{OB} 12012 N 11$, Colorcon - England. Diluent: lactose monohydrate (lot $\mathrm{n}^{\circ}$ 10162230), Granulac $\AA$ 200, Meggle, Wasserburg, Germany. Glidant: Talc. Lubricant: magnesium stearate (Magnesia GmbH, Germany).

Dulbecco's modified Eagle's medium (DMEM), ethylenediamine tetraacetic acid (EDTA), nonessential amino acids (NeAA), phosphate buffer saline solution (PBS$\mathrm{KH}_{2} \mathrm{PO}_{4}-15 \mathrm{mM}, \mathrm{NaHPO}_{4}-43 \mathrm{mM}, \mathrm{KCl}-27 \mathrm{mM}, \mathrm{pH} 7.4$ ), potassium chloride, potassium phosphate monobasic, sodium bicarbonate, sodium chloride, sodium pyruvate, sulforhodamine B (SRB), Trypan blue $(0.04 \%$ (w/v) solution in PBS), Tris(hydroxymethyl)aminomethane, as well as all the reagents and media for cell culturing, were supplied by Sigma-Aldrich (Portugal). Fetal bovine serum (FBS) lot $\mathrm{n}^{\circ} 41 \mathrm{~F} 3676 \mathrm{~F}$ and trypsin/EDTA were purchased from GIBCO (Spain).

The human Caucasian colon adenocarcinoma cell line Caco-2 was made available by IPATIMUP (Institute of Molecular Pathology and Immunology of the University of Porto, Portugal).

\section{Preparation of the matrix tablets}

The distinct formulations of the matrix tablets analyzed along this study are comprised in Table 1. Both drug and excipients were sieved (125 mesh) and thoroughly mixed in a plastic bag for $15 \mathrm{~min}$. Talc and magnesium stearate were sieved (200 mesh), added to the previous mixture and blended for $5 \mathrm{~min}$ more. All matrices containing $300 \mathrm{mg}$ of zidovudine were directly compacted in an automatic hydraulic press (Specac Press, UK), using flat $10 \mathrm{~mm}$ diameter punches and a compaction pressure of $100 \mathrm{MPa}^{42}$.

\section{Raman spectroscopy}

The Raman spectra were obtained on a triple monochromator Jobin-Yvon T64000 Raman system (focal distance $0.640 \mathrm{~m}$, aperture $f / 7.5$ ) equipped with holographic gratings of 1800 grooves. $\mathrm{mm}^{-1}$. The premonochromator stage was used in the subtractive mode. The detection system was a liquid nitrogen cooled non-intensified $1024 \times 256$ pixel (1") Charge Coupled Device (CCD) chip. A coherent (model Innova 300-05) $\mathrm{Ar}^{+}$laser was used as the light source, the output of which, at $514.5 \mathrm{~nm}$, was adjusted to provide $80 \mathrm{~mW}$ at the sample position. A $90^{\circ}$ geometry, between the incident radiation and the collecting system, was employed. The entrance slit was set to $100 \mu \mathrm{m}$. Up to 10 to 20 scans, with integration times between 12 and 30 s, were used in all experiments.

Samples were sealed in Kimax glass capillary tubes of $0.8 \mathrm{~mm}$ inner diameter. Under the above mentioned conditions, the error in wavenumbers was estimated to be within $1 \mathrm{~cm}^{-1}$.

\section{Weight, diameter, thickness, hardness, and friability of the tablets}

A total of 20 tablets were checked for weight uniformity (KERN 770, electronic balance, Germany), diameter, 
Table 1. Composition of the distinct AZT formulations containing hydrophilic and hydrophobic polymers.

\begin{tabular}{|c|c|c|c|c|c|c|c|c|c|}
\hline \multirow[b]{2}{*}{ Formulations } & \multicolumn{9}{|c|}{ Components (mg) } \\
\hline & $\mathrm{AZT}$ & HPMC K 100M & HPMC K 15M & EC & ERS PO & ERL PO & Lactose & Talc & Mg Stearate \\
\hline F1 & 300.0 & - & - & 46.0 & - & - & 30.0 & 2.0 & 2.0 \\
\hline $\mathrm{F} 2$ & 300.0 & - & - & 38.0 & - & - & 38.0 & 2.0 & 2.0 \\
\hline F3 & 300.0 & - & - & 26.0 & - & - & 50.0 & 2.0 & 2.0 \\
\hline $\mathrm{F} 4$ & 300.0 & - & - & 23.0 & - & - & 53.0 & 2.0 & 2.0 \\
\hline F5 & 300.0 & - & - & - & 23.0 & 23.0 & 30.0 & 2.0 & 2.0 \\
\hline F6 & 300.0 & - & - & - & 20.0 & 26.0 & 30.0 & 2.0 & 2.0 \\
\hline F7 & 300.0 & - & - & - & 38.0 & 38.0 & - & 2.0 & 2.0 \\
\hline F8 & 300.0 & - & - & - & 20.0 & 56.0 & - & 2.0 & 2.0 \\
\hline F9 & 300.0 & 23.0 & 23.0 & - & - & - & 30.0 & 2.0 & 2.0 \\
\hline F10 & 300.0 & 19.0 & 19.0 & - & - & - & 38.0 & 2.0 & 2.0 \\
\hline F11 & 300.0 & 13.0 & 13.0 & - & - & - & 50.0 & 2.0 & 2.0 \\
\hline F12 & 300.0 & 11.5 & 11.5 & - & - & - & 53.0 & 2.0 & 2.0 \\
\hline F13 & 300.0 & - & - & 23.0 & 11.5 & 11.5 & - & 2.0 & 2.0 \\
\hline F14 & 300.0 & - & - & 26.0 & 10.0 & 10.0 & 30.0 & 2.0 & 2.0 \\
\hline F15 & 300.0 & - & - & 38.0 & 19.0 & 19.0 & - & 2.0 & 2.0 \\
\hline F16 & 300.0 & - & - & 56.0 & 10.0 & 10.0 & - & 2.0 & 2.0 \\
\hline F17 & 300.0 & 11.5 & 11.5 & - & 11.5 & 11.5 & 30.0 & 2.0 & 2.0 \\
\hline F18 & 300.0 & 13.0 & 13.0 & - & 10.0 & 10.0 & 30.0 & 2.0 & 2.0 \\
\hline F19 & 300.0 & 19.0 & 19.0 & - & 19.0 & 19.0 & - & 2.0 & 2.0 \\
\hline F20 & 300.0 & 13.0 & 13.0 & - & 25.0 & 25.0 & - & 2.0 & 2.0 \\
\hline
\end{tabular}

thickness (Precision micrometer, Roche, Switzerland), hardness (TAXT plus texture analyzer, UK), and friability (Erweka TA 20, Germany).

\section{In vitro release studies}

AZT release from different formulations was measured for $12 \mathrm{~h}$, at $37^{\circ} \mathrm{C} \pm 2.0^{\circ} \mathrm{C}$, by the USP Method 1 (USP31, 2008) in $900 \mathrm{~mL}$ of dissolution media- either simulated gastric ( $\mathrm{pH}$ 1.2) or intestinal (phosphate buffer $\mathrm{pH}$ 6.8) fluids without enzymes- using a dissolution apparatus (Vankel VK-7000 dissolution testing station, Edison, NJ, USA) with a stirring speed of $50 \mathrm{rpm}$.

Sink conditions were kept constant throughout the test. The matrices were initially placed in simulated gastric fluid. After $2 \mathrm{~h}$, the $\mathrm{pH}$ of the medium was varied from 1.2 to 6.8 (simulated intestinal fluid). At suitable intervals, $5 \mathrm{~mL}$ samples were withdrawn and immediately replaced with equal volumes of the respective dissolution medium (maintained at $37 \pm 2.0^{\circ} \mathrm{C}$ ). The samples were filtered ( $45 \mu \mathrm{m})$, diluted, and spectrophotometrically analyzed for the AZT content, at $\lambda=266 \mathrm{~nm}$, according to the validation procedure previously described ${ }^{43}$.

The drug release profiles were represented through plots of the cumulative percentage of drug release (calculated from the total amount of AZT contained in each matrix) versus time. Each independent experiment was performed in triplicate.

\section{Kinetic mechanism and release parameters}

The tablet's dissolution profiles can be characterized following mathematical model-dependent or modelindependent methods ${ }^{44}$. According to the extensively used model-dependent approach, the release kinetics of zidovudine formulations was described by finding the best fit of the data (fraction of drug released versus time) to distinct mathematical functions: zero-order, firstorder, Higuchi ${ }^{45,46}$ and Hixson-Crowell ${ }^{47}$. Furthermore, to gain some insight into the drug release mechanism, the Korsmeyer-Peppas semi-empirical model was applied ${ }^{48}$. After fitting these models to the dissolution data, their performance was based on the determination coefficient $\left(\mathrm{r}^{2}\right)$ comparison.

On the other hand, model-independent methods included: the time to release $\mathrm{x} \%$ of drug from the tablet $\left(t_{x \%}\right)$, the sampling time $\left(\%_{\mathrm{yh}}\right)$, that is, the percentage of drug release after $y$ hours, the mean dissolution times $(M D T)$ and the dissolution efficiency $(D E)$.

$M D T$ was calculated in accordance with the following Equation (1):

$$
M D T=\frac{\sum_{\mathrm{j}=1}^{\mathrm{n}} \hat{t}_{j} \Delta Q_{j}}{\sum_{\mathrm{j}=1}^{\mathrm{n}} \Delta Q_{j}},
$$

where $j$ is the sample number, $n$ the number of time increments considered, $\hat{t}_{j}$ is the time at midpoint between $t_{j}$ and $t_{j-1}$; and $\Delta Q_{j}$ is the additional amount of drug dissolved in the period of time between $t_{i}$ and $t_{i-1}$.

$D E$, in turn, is defined for a pharmaceutical dosage form ${ }^{49,50}$ as the area under the dissolution curve for a certain period of time expressed as a percentage of the area of the rectangle that represents $100 \%$ dissolution at the same time point. It can be calculated by the Equation (2), $y$ being the drug percentage dissolved at time $t$. 


$$
D E=\frac{\int_{0}^{\mathrm{t}} y \times d t}{y_{100} \times t} \times 100 .
$$

Moreover, two model-independent methods were used to compare the drug dissolution profiles: the difference factor $\left(f_{1}\right)$ and the similarity factor $\left(f_{2}\right)^{51-54}$. The $f_{1}$ factor measures the percentage error between two curves (Equation (3)):

$$
f_{1}=\frac{\sum_{\mathrm{t}=1}^{\mathrm{n}}\left|R_{\mathrm{t}}-T_{\mathrm{t}}\right|}{\sum_{\mathrm{t}=1}^{\mathrm{n}} R_{\mathrm{t}}} \times 100,
$$

where $n$ is the number of dissolution sample times, and $R_{t}$ and $T_{t}$ are either the individual or mean percentage dissolved of either the reference or test products at each time point $t$, respectively. This factor is 0 , when the test and drug reference dissolution profiles are identical, and increases proportionally with their difference.

The $f_{2}$ factor is a logarithmic reciprocal square root transformation of one plus the mean squared differences of the drug percentage dissolved between the reference and test products (Equation (4)):

$$
f_{2}=50 \log \left\{\left[1+(1 / n) \sum_{\mathrm{t}=1}^{\mathrm{n}}\left|R_{\mathrm{t}}-T_{\mathrm{t}}\right|^{2}\right]^{-1 / 2} \times 100\right\} .
$$

This similarity factor is 100 when the reference and test dissolution profiles are identical and tends to 0 as the dissimilarity increases. Two dissolution profiles are declared similar, if the $f_{1}$ value is lower than 15 (15 to 0 ) and $f_{2}$ is higher than 50 (50 to 100).

\section{In vitro studies on the Caco- 2 cell line Preparation of the drug solutions for in vitro assays}

The choice of the drug concentrations to be screened in the cell cultures as to their antiproliferative and/or cytotoxic effect was based on the drug release profiles previously obtained. Therefore, solutions (prepared in PBS) were added to the cells sequentially, at 3, 6, 9, 12, and $24 \mathrm{~h}$, attaining final concentrations of $92 \mu \mathrm{M}$ for F9, $97 \mu \mathrm{M}$ for F10, and $99 \mu \mathrm{M}$ for F19.

The solutions were stored at $5^{\circ} \mathrm{C}$ and protected from light. Before administration to the cell cultures, they were filtered under sterile conditions $(0.22 \mu \mathrm{m}$ Nylon syringe filter with a Luer lock).

\section{Cell culture}

The human Caucasian colon adenocarcinoma cell line Caco-2 (grown in monolayers) was kept at $37^{\circ} \mathrm{C} \pm 0.5^{\circ} \mathrm{C}$, under $5 \% \mathrm{CO}_{2}$, in DMEM, supplemented with $10 \%$ heatinactivated FBS, 1\% NeAA, sodium pyruvate and antibiotics (100 UI.ml ${ }^{-1}$ penicillin/100 $\mu \mathrm{g} \cdot \mathrm{ml}^{-1}$ streptomycin).
Cells were subcultured twice a week, and were harvested upon addition of trypsin/EDTA (0.05\% trypsin, $0.35 \mathrm{mM}$ EDTA.4Na reconstituted in free $\mathrm{Ca}^{2+}$ and $\mathrm{Mg}^{2+}$ balanced salt solution).

\section{Cell morphology changes}

To assess the drug effect on cell morphology, the cultures were observed at the microscope (after staining with Trypan blue) upon $48 \mathrm{~h}$ of incubation with zidovudine, for each formulation tested. The antiviral was then removed, the cells were washed with PBS, and their morphological aspect was once more examined after an additional $24 \mathrm{~h}$ of incubation in drug-free medium.

\section{Antiproliferative activity and cytotoxicity evaluation}

Cell density and cell viability following drug exposure were assessed with the use of standard assays. Cells were plated at $1.0 \times 10^{5}$ cells. $\mathrm{ml}^{-1}$ in 24 -well dishes and incubated overnight ( $24 \mathrm{~h})$ to allow for cell attachment. After seeding, zidovudine (in solution, either pure or in a formulation) was added to the medium (at the 3, 6, 9, 12 , and $24 \mathrm{~h}$ time points) and the cultures were further incubated at $37^{\circ} \mathrm{C} \pm 0.5^{\circ} \mathrm{C}$ for $24 \mathrm{~h}$. For each formulation, as well as for pure AZT, cells were harvested and analyzed (both in controls and in drug-treated cultures), and the AZT solution was replaced gradually each $3 \mathrm{~h}$, to obtain the drug concentration corresponding to the release studies, for each experimental condition. Cell proliferation and viability were evaluated through the SRB staining assay ${ }^{55-59}$. The optical density of the samples was measured at $540 \mathrm{~nm}$, in a microplater reader (Biotek $\mu$ Quant MQX200, Sweden).

\section{Reversibility of the drug effect}

Cells were seeded at $1.0 \times 10^{5}$ cells. $\mathrm{ml}^{-1}$, grown to $80 \%$ confluence and exposed to zidovudine (for each formulation and also for pure AZT) for $24 \mathrm{~h}$. Reversibility of the drug effect was then tested by replacing the drug-containing medium by fresh culture medium and assessing the cell viability following an additional 3 days of incubation. Cell density and viability were determined by the SRB method.

\section{Statistics}

All experiments were carried out in triplicate. The results are expressed as mean values \pm SD (the corresponding error bars being displayed in the graphical plots).

Statistical analyses were performed using analysis of variance (ANOVA), followed by post hoc test of Fisher's Protected Least Significant Difference. In view of assessing the statistical significance between the data, a single-factor ANOVA was carried out, at a 5\% significance level. Additionally, the post-test and Bonferroni multiple comparison were performed, which related pairs of individual samples, checking that the values were statistically different. The software SPSS Statistics for Windows (version 16.0) was used in this analysis. 


\section{Results and discussion}

\section{Preformulation studies}

Excipients containing reactive functional groups may give rise to chemical and physical transformations. Thus, when studying new pharmaceutical formulations, it is important to determine the presence of possible incompatibilities between their components. Raman spectroscopy, which has been widely applied to this type of preformulation studies ${ }^{60-63}$, was presently used with a view to detect solid-state interactions between AZT and the considered excipients and, consequently, to assess the drug-excipients compatibility in all examined formulations. A 1:1 ( $w: w)$ drug:excipient ratio was chosen, since this is known to maximize the likelihood of observing intermolecular interactions.

Raman spectra in the $150-3650 \mathrm{~cm}^{-1}$ region are presented in Figure 1, for both AZT and each of the pure polymers used. An analysis of these spectra revealed very strong similarities between different forms of hydroxypropylmethylcellulose (HPMC K15M and K100M; Figures 1B

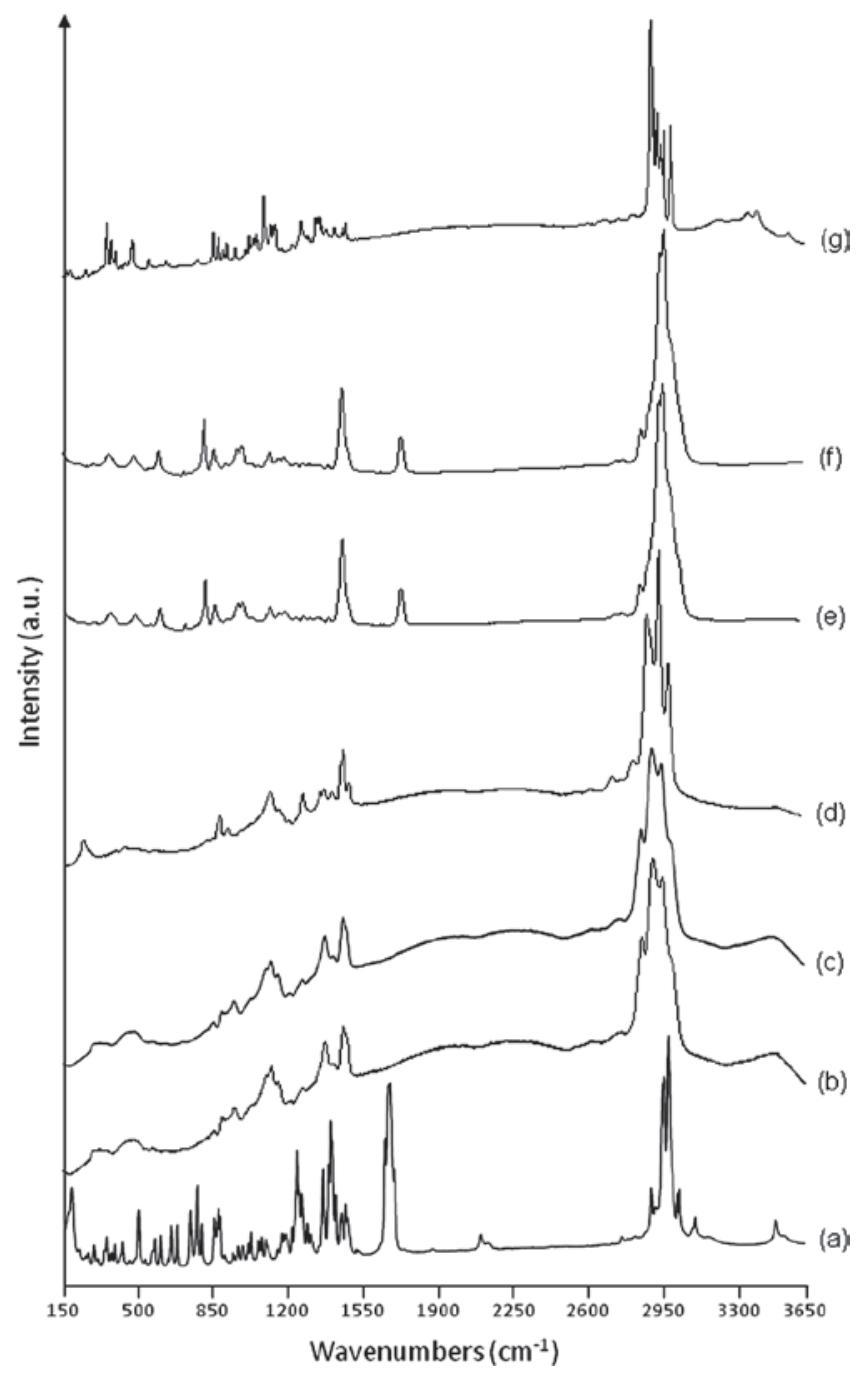

Figure 1. Raman spectra, in the $150-3650 \mathrm{~cm}^{-1}$ region, of AZT (a), HPMC K15M (b), HPMC K100M (c), etilcelulose (d), Eudragit ${ }^{\circledR}$ RL PO (e), Eudragit ${ }^{\circledR}$ RS PO (f), and lactose (g). and C, respectively). The same is observed to Eudragits ${ }^{\circledR}$ (RL PO and RS PO; Figure $1 \mathrm{E}$ and F, respectively).

Figures 2A and A comprise the Raman spectra of the AZT:HPMC K15M and AZT:Eudragit ${ }^{\circledR}$ RS PO physical mixtures, respectively. In an attempt to detect changes in the drug molecule upon mixing with each polymer, these spectra were subtracted from those of the excipients (Figures 2B and 3B) to obtain the "AZT changed" spectra (Figures 2C and 3C). The similarity between the latter and the spectrum of pure AZT (Figure 1A) allows to conclude that there are no significant intermolecular interactions that could eventually lead to an incompatibility between the drug and the different excipients tested (the results for the remaining excipients are present as Supplementary Data in Figures S1-S4).

\section{Physical characteristics of AZT-containing matrices}

The technological characteristics of the mixtures allows the preparation of tablets with a uniform weight as indicated by the very low standard deviation in all formulations, well inside the pharmacopoeia limits (R.S.D. $<1 \%$, Table S1).

It is well known that tablets' thickness values may vary, depending of the flow characteristics of the powders. The assessments made in the formulations under study show low thickness relative standard deviation $(<$ $1 \%$ ), evidencing that the powder filled the punch cavity homogeneously due to its good flow behavior.

The matrices' hardness always remained within acceptable limits (96-103 N). However, as this analysis is not an absolute indicator of strength, friability was also measured: in all formulations, tablets friability was less than $1 \%$, within the USP 31 limits. Small values imply much less friability during transportation, which

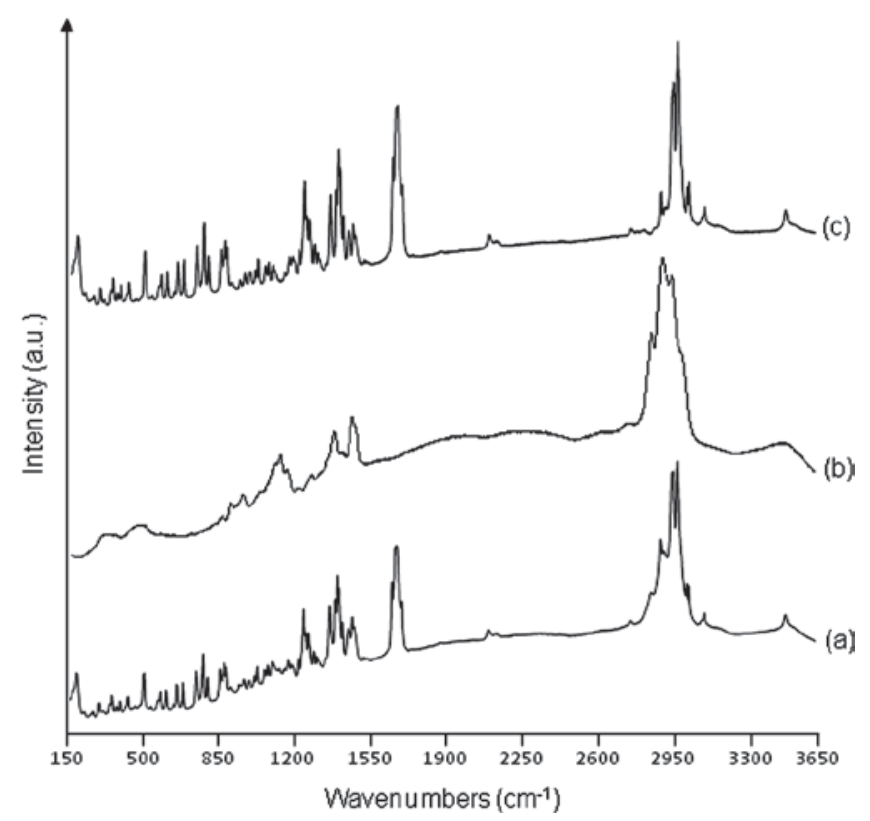

Figure 2. Raman spectra, in the $150-3650 \mathrm{~cm}^{-1}$ region, of AZT:HPMC K15M physical mixture (a), pure HPMC K15M (b), and the result of subtraction (c). 


\section{J.V. Santos et al.}

is important in terms of tablets. Moreover, there was accordance between friability and hardness assessments (Table S1).

\section{Drug release analysis}

Drug release from hydrophilic matrices was found to be affected by: (a) water diffusion through the matrix; (b) drug diffusion through the hydrated matrix; and (c) erosion of the hydrated matrix. The ratios of AZT released from the matrices, for a 12 -h period, are depicted in Figures 4-8. As can be observed, the ratio for all formulations does not show statistically significant differences $(p>0.05)$ from unity, in any case.

Polymeric matrices containing ethylcellulose alone (F1-F4) did not attain the desired release profile. Due to total breakdown of the tablet, virtually all the AZT was dissolved after $4 \mathrm{~h}$ (Figure 4). However the results suggested that ethylcellulose has the ability to modulate

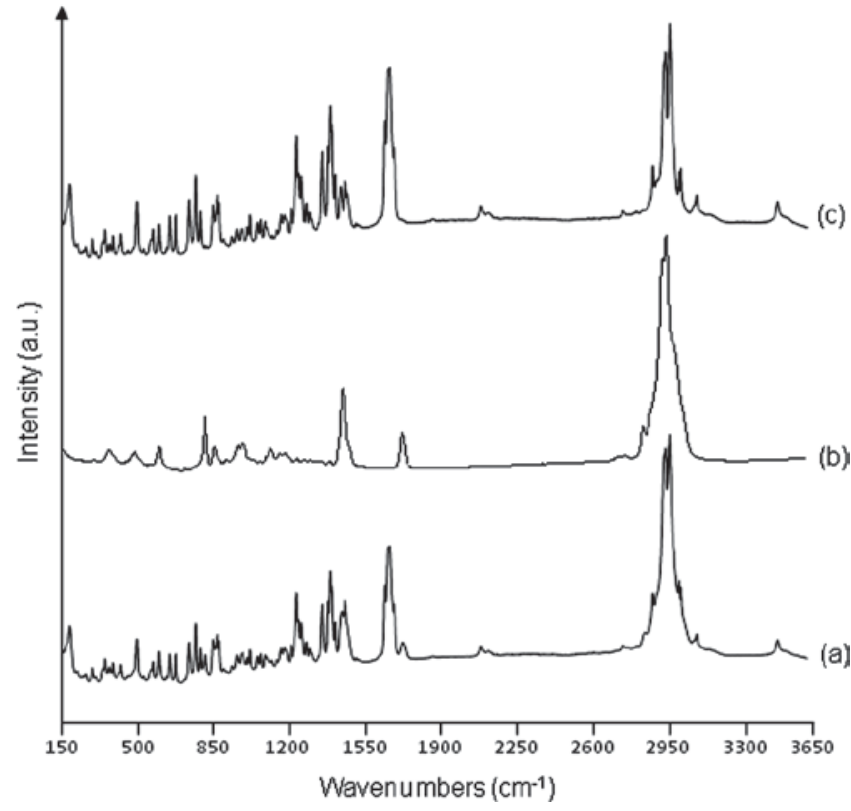

Figure 3. Raman spectra, in the $150-3650 \mathrm{~cm}^{-1}$ region, of AZT: Eudragit ${ }^{\circledR}$ RS PO physical mixture (a), pure Eudragit ${ }^{\circledR}$ RS PO (b), and the result of subtraction (c).

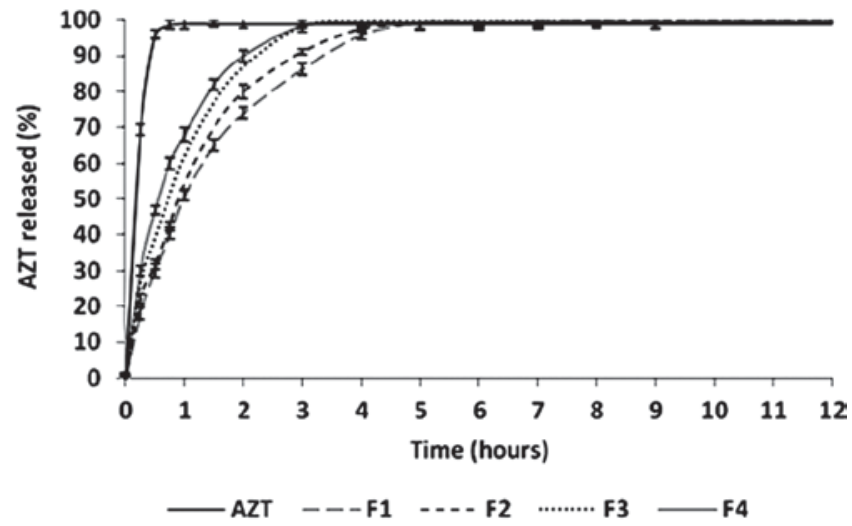

Figure 4. Drug-release profiles for zidovudine formulations containing ethylcellulose.

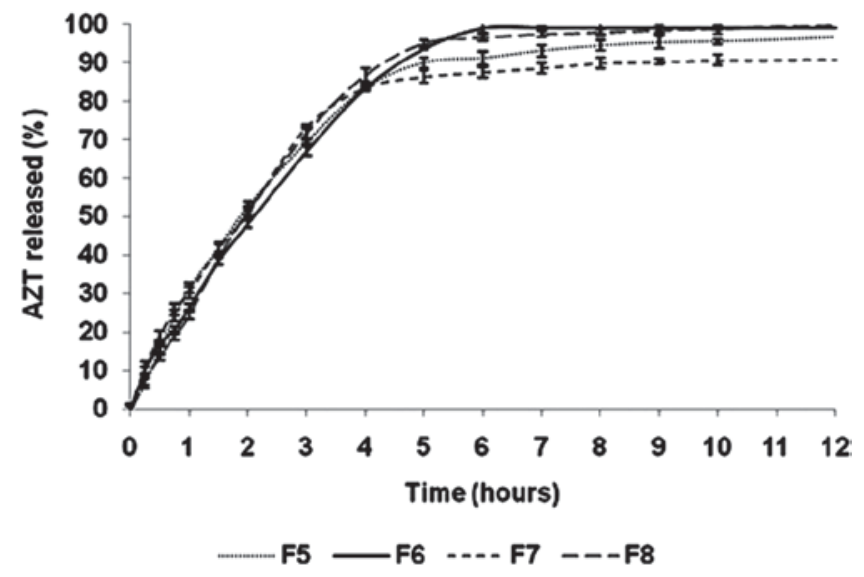

Figure 5. Drug-release profiles for zidovudine formulations containing: Eudragit ${ }^{\circledR}$ RS PO and Eudragit ${ }^{\circledR}$ RL PO.

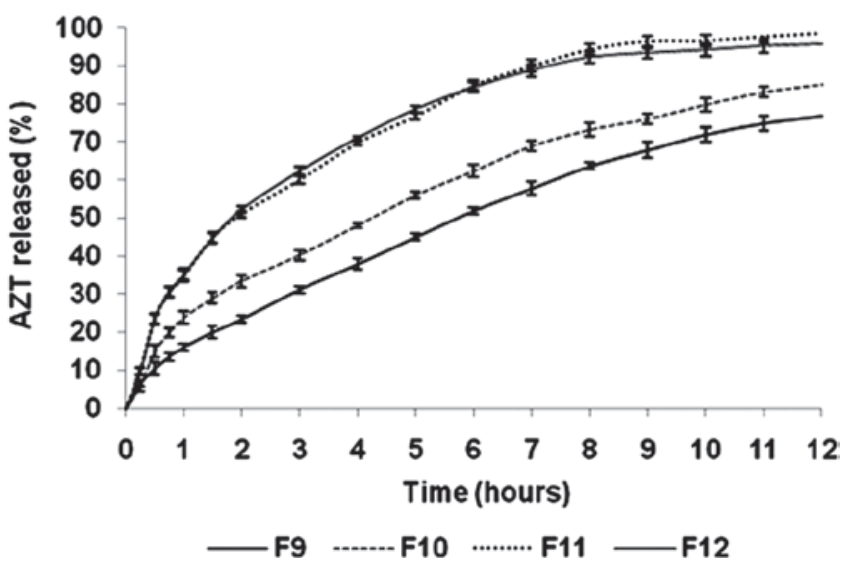

Figure 6. Drug-release profiles for zidovudine formulations containing: HPMC K15M and HPMC K100M.

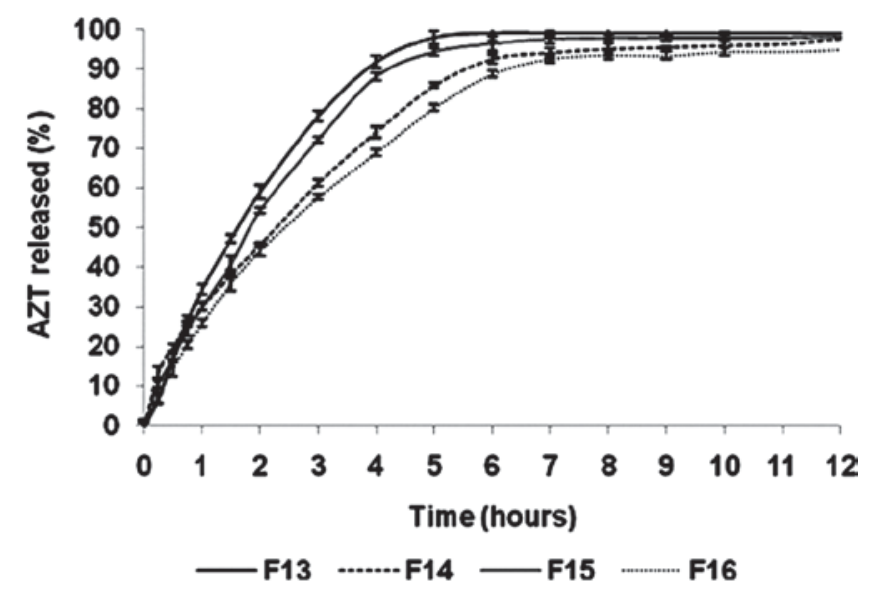

Figure 7. Drug-release profiles for zidovudine formulations containing: EC, Eudragit ${ }^{\circledR}$ RS PO and RL PO.

the dissolution profiles of the other polymers presently studied.

The dissolution profiles of the tablets containing both Eudragit ${ }^{\circledR}$ RS PO and RL PO, in different binary mixtures (F5-F8), evidence a slight dependence on Eudragit ${ }^{\circledR}$ RS PO quantity (Figure 5). Formulations F6 and F8, which 


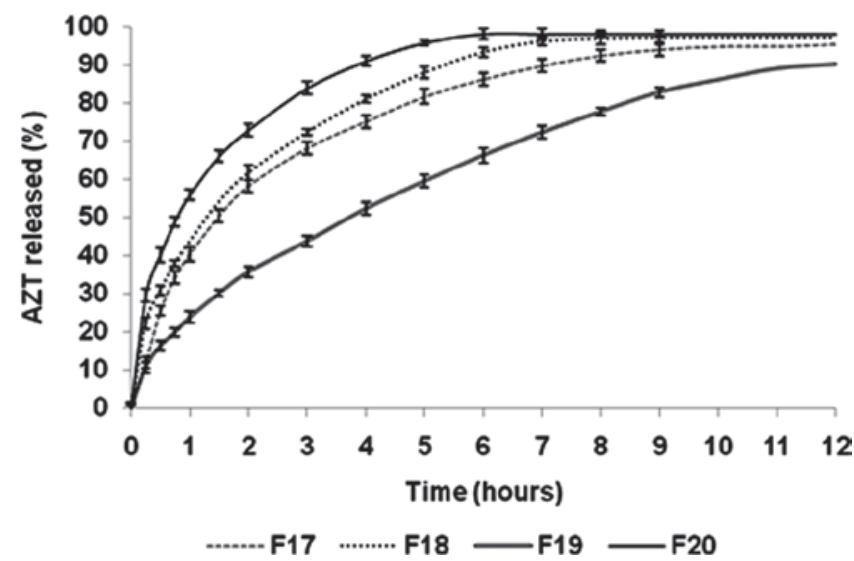

Figure 8. Drug-release profiles for zidovudine formulations containing: HPMC K15M:K100M and Eudragit ${ }^{\circledR}$ RS:RL PO.

have the same amount of Eudragit ${ }^{\circledR}$ RS PO (low permeability) and a roughly 1:2 ratio of Eudragit ${ }^{\circledR}$ RL PO (high permeability), show virtually superimposed release profiles, evidencing a weak influence of the latter. On the other hand, increasing the amount of Eudragit ${ }^{\circledR}$ RS PO (F6, F8 < F5 < F7) causes a detectable decrease in the quantity of drug released (Figure 5). However, although these formulations were shown to be able to prolong the release of antiviral (when compared with those containing only ethylcellulose (F1-F4)), they did not meet the criteria required for an extended release, since more than $80 \%$ of the drug was liberated after $4 \mathrm{~h}$.

The use of HPMC, either K100M or K15M, as the sole excipient in the matrix was also tested, but the drug was not released in a $24-\mathrm{h}$ interval. Thus, matrices containing both HPMC K15M and HPMC K100M were then prepared (F9-F12) and their dissolution profile was analyzed (Figure 6). By simple observation, during the release tests, it may be concluded that the drug diffusion coefficient was dependent on the water quantity in the tablets. The diffusion is very slow, since the water may act as a plasticizer or form stable bonds (hydrogen bonds) between these polymers.

Tablets comprising a high quantity of HPMC (F9 and F10) presented a delayed drug release when compared with the ones containing a low proportion of polymers (Figure 6). This confirms that the drug:polymer ratio is an important factor affecting the drug release rates from HPMC matrices ${ }^{64-66}$. The gel layer that is formed delays further water uptake and the release of the dissolved drug. The percentages of released AZT from the simple HPMC mixtures tested were between $76.0 \%$ and $84.1 \%$, after $12 \mathrm{~h}$.

Although the formulations containing only ethylcellulose (F1-F4) correspond to a drug release higher than $90 \%$ in $4 \mathrm{~h}$, it was decided to associate this polymer with the Eudragits (F13-F16), as some studies have reported its ability to delay the release process ${ }^{67,68}$. In fact, the AZT release profiles presently obtained seem to be dependent of the EC:Eudragit ${ }^{\circledR}$ proportion: matrices with a unit ratio (F13 and F15) displaying very similar release profiles (Figure 7), and as the EC/Eudragit ${ }^{\circledR}$ ratio is increased (1.3 for F14 and 2.8 for F16), the drug release becomes slower. Moreover, the zidovudine release after $12 \mathrm{~h}$ appears to be virtually independent of the ethylcellulose quantity ( $94.0 \%$ to $99.1 \%$ ).

After testing binary and ternary mixtures, quaternary ones were used. Formulations containing both HPMC and Eudragit ${ }^{\circledR}$ (F17-F20) gave rise to AZT dissolution values between $90.5 \%$ and $98.1 \%$ after $12 \mathrm{~h}$ (Figure 8 ). In general, the process of tablet swelling was very rapid, leading to a fast release of the drug (higher in gastric than in intestinal medium). A significant increase in the zidovudine release rate was observed for decreased HPMC proportions. The best profile appear to correspond to the F19 formulation: it promotes a slightly faster initial drug release coupled to a slower transfer, while allowing the use of over $90 \%$ of the drug.

The change in the dissolution medium (from gastric to intestinal) $2 \mathrm{~h}$ after adding the initial one, allowed to conclude that different $\mathrm{pH}$ conditions do not generate discontinuities in the drug release profile.

It is generally assumed that water soluble drugs are released primarily by diffusion through the "gel layer" and that scarcely water soluble drugs are released mainly through erosion of this layer. Actually, the release mechanism is dictated by the solubility of the drug and both mechanisms contribute to the release. It is the relative input from each process that is controlled by the drug's solubility ${ }^{69}$.

The analysis of the drug release behavior for the various combinations studied allows verifying that the F9, F10, and F19 mixtures can provide kinetics suitable for extended release formulations, according to the objectives set.

\section{Kinetic mechanism and release parameters}

Dissolution tests at different dissolution $\mathrm{pH}$ values should be considered, in a preformulation study, in view of assessing the good functionality of the therapeutic system. Drug release is controlled by different mechanisms with diverging kinetics. Using a gelling agent of low viscosity grade (HPMC K15M), erosion of the swollen polymer describes the release mechanism ${ }^{70}$. In turn, if high viscosity polymers are applied (HPMC K100M), a stable gel is formed and polymer erosion is negligible. In addition, the use of water insoluble polymers as tablet excipients partly contributed to the prevention of matrix disintegration.

Usually, both erosion and diffusion contribute to the release of an incorporated drug. The transition between the two mechanisms results in a kinetic process generally described as "anomalous transport," considered when there is the contribution of both diffusion and relaxation processes $^{70-72}$. The analysis of present experimental data in the light of the Korsmeyer-Peppas formalism, as well as the interpretation of the corresponding release exponent values $(n)$, leads to a better understanding of the balance between these mechanisms. Moreover, the 
kinetics of AZT release was also determined by finding the best fit of the dissolution data (fraction of drug release versus time) to distinct models: zero-order, first-order, Higuchi, and Hixson-Crowell. This kind of analysis was performed for F9, F10, and F19 selected formulations: the AZT release profiles (between $10 \%$ and $70 \%$ ) were fitted and the results are summarized in Table 2.

The obtained values for the Korsmeyer-Peppas diffusion exponent $n$ (0.57-0.65) suggest that zidovudine release from F9, F10, and F19 matrices is controlled by both drug diffusion in the hydrated matrix and erosion of the matrix. As a result, good fits to both Higuchi (Fickian diffusion) and Hixson-Crowell models were achieved (the latter being mainly related with changes in the surface area and diameter of the tablets).

Following the well-known Flick's law, zidovudine diffuses through the stable gel layer according to a square root time dependence. In the swelling tablet surface, the water molecules diffuse with more difficulty from these matrices, since at the beginning of the dissolution studies, a gel barrier is formed. On the other hand, the time for the polymer to relax also decreases and the relaxation mechanism becomes more pronounced. The mechanisms of drug release from a polymeric matrix occur in the early stage by polymer swelling and the tablet thickness increases. The results indicated that the mechanism of drug release was diffusion coupled with erosion (anomalous transport).

The release parameters obtained for the selected formulations are listed in Table 3. Although the MDT values are quite similar, those for F9, F10, and F19 formulations are slightly higher than the ones obtained for the remaining formulations (Table S2). In fact, the percentage of HPMC polymer in the tablets may modify the matrix swelling and the release rates. In addition, it is proposed that the rate and the drug release mechanism from HPMC matrices is almost independent of the ionic strength of the medium ( $\mathrm{pH}=1.2$ and $\mathrm{pH}=6.8)$. A significant decrease in drug release can be achieved by using a higher amount of HPMC K15M:HPMC K100M (F9 $\left.\%_{12 \mathrm{~h}}=77\right)$.

To compare the MDT profiles obtained, the differences between the parameter estimates from each fit are calculated and a joint confidence region around the vector of mean differences is established using the Bonferroni test. The $F$-test indicated that the general level of the profiles is similar for both batches. Concerning the other F-test, Bonferroni test evidenced that the assumptions about the variance matrix of the F9 and F10 were similar. This means that, according to this test, the general shape of the batches' profiles is different when a level of significance of $5 \%$ is considered.

The influence of polymeric matrices on the rate and extent of zidovudine release was evaluated (Table 3). A significant improvement on the release and extension rate of the formulations was observed, with a $\mathrm{DE}_{2 \mathrm{~h}}$ of $14.76 \%$ to $22.55 \%$. The analysis of variance of the $\mathrm{DE}$ values shows that the formulation release profiles under study are not similar $(p>0.05)$.

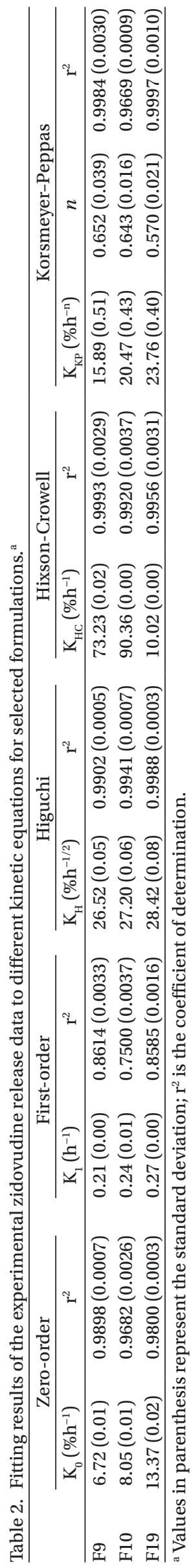

Drug Development and Industrial Pharmacy 
The similarity factor $\left(f_{2}\right)$ has been adopted by US Food and Drug Administration ${ }^{52}$ and European Medicines Agency $^{73,74}$ as a criterion for assessment of similarity between two in vitro release profiles. Therefore, in the present study, $f_{2}$ was employed to evaluate the release profiles of various formulations.

This type of factor analyses are based on a comparison between the obtained results and the release profile considered as ideal. For the type of matrices used, containing either hydrophilic or hydrophobic polymers, two optimal profiles were considered: (i) an ideal Higuchi profile for a total release of the drug in $12 \mathrm{~h}\left(\mathrm{~K}_{\mathrm{H}}=100 / 12^{1 / 2}\right)$ and (ii) an ideal target profile based on data from the literature (release after 2 h: $35 \%$; after 4 h: $52 \%$; after 8 h: $75 \%$ ) according to Table $4^{75,76}$.

The $f_{1}$ (difference factor) is proportional to the average difference between two profiles, whereas $f_{2}$ is inversely proportional to the average squared difference between the two profiles, with emphasis on the larger difference among all time points. In fact, $f_{2}$ is a logarithmic transformation of the sum-squared error of differences between the testing drug release $\mathrm{T}_{t}$ and the ideal release $\mathrm{R}_{t}$ over all time points $(n)$. When $f_{2}$ was $>50$, the mean deviation over all time points was less than $10 \%$, and the testing profile was believed to be similar to the ideal profile. As $f_{1}$ and $f_{2}$ are strongly dependent on the last considered release point ( $>85 \%$ ), only the release values between $0 \%$ and $85 \%{ }^{51-54}$ were accounted for in the analysis (Table 5).

Table 3. Release parameters for selected zidovudine formulations.

\begin{tabular}{lrrr}
\hline & \multicolumn{3}{c}{ Formulations } \\
\cline { 2 - 4 } Parameters & \multicolumn{1}{c}{ F9 } & \multicolumn{1}{c}{ F10 } & \multicolumn{1}{c}{ F19 } \\
\hline $\mathrm{t}_{25 \%}(\mathrm{~h})$ & $2.18 \pm 0.87$ & $1.24 \pm 0.95$ & $1.05 \pm 0.99$ \\
$\mathrm{t}_{50 \%}(\mathrm{~h})$ & $5.90 \pm 1.12$ & $4.01 \pm 0.99$ & $3.66 \pm 1.03$ \\
$\%_{12 \mathrm{~h}}{ }^{\mathrm{a}}$ & $76.92 \pm 0.99$ & $84.12 \pm 1.18$ & $90.50 \pm 1.09$ \\
$\mathrm{MDT}^{\mathrm{a}}(\mathrm{h})$ & $4.53 \pm 0.02$ & $3.84 \pm 0.03$ & $3.85 \pm 0.04$ \\
$\mathrm{DE}_{2 \mathrm{~h}}{ }^{\mathrm{a}}(\%)$ & $14.76 \pm 1.17$ & $20.63 \pm 0.96$ & $22.55 \pm 1.13$ \\
$\mathrm{DE}_{12 \mathrm{~h}}{ }^{\mathrm{a}}(\%)$ & $48.07 \pm 1.23$ & $57.61 \pm 0.99$ & $61.46 \pm 0.99$ \\
\hline
\end{tabular}

${ }^{\mathrm{a}}$ Mean \pm S.D. (six measurements).

Table 4. Zidovudine ideal release profiles for a 12 -h $\mathrm{h}$ release period (see text).

\begin{tabular}{lcc}
\hline Time (hours) & Ideal target $(\%)$ & Higuchi $(\%)$ \\
\hline 0 & 0 & 0 \\
1 & 20 & 29 \\
2 & 35 & 41 \\
3 & 44 & 50 \\
4 & 52 & 58 \\
5 & 59 & 65 \\
6 & 65 & 71 \\
7 & 70 & 76 \\
8 & 75 & 82 \\
9 & 80 & 87 \\
10 & 84 & 91 \\
11 & 88 & 96 \\
12 & 92 & 100 \\
\hline
\end{tabular}

The F9 $f_{1}$ and $f_{2}$ values clearly indicate that this formulation does not conform to the desired release profile (Table 5, Figure 9). In turn, formulations F10 and F19 showed a clear similarity regarding both the Higuchi profile and the ideal target profile established in the present work. In particular, F19 which contains a mixture of HPMC and Eudragits ${ }^{\circledR}$ with identical masses and without the use of lactose as a diluent, displays a strong resemblance with the ideal target profile (Figure 9), thus presenting $f_{1}$ and $f_{2}$ values (2.7 and 82.5, respectively) well within the FDA and EMEA criteria $\left(f_{1} \leq 15\right.$ and $\left.f_{2} \geq 50\right)^{52,73,74}$.

\section{Cell morphology assessment and evaluation of cell growth inhibition and cytotoxicity}

The evaluation of the effect of the AZT formulations presently investigated at a cellular level was initially based on a microscopic observation of the Caco-2 cultures, to understand the morphology and typical organization of this cell line, both in the absence and in the presence of the drug. Since these cells have a clear tendency to form colonies, they were plated at an appropriate density to allow this type of distribution. In the drug-free cultures, the isolated cells were found to migrate and start to form small colonies, which steadily increased in size. In the presence of each AZT formulation, in turn, morphological changes were observed, namely disruption of the cellular layer and finally cell lysis.

Furthermore, growth-inhibition and cytotoxicity evaluation tests were carried out for each of the AZT solid matrices studied, as well as for the pure drug (for

Table 5. Difference $\left(f_{1}\right)$ and similarity $\left(f_{2}\right)$ factors for a $0-85 \%$ of AZT release from selected formulations, relative to both Higuchi and target ideal release profiles.

\begin{tabular}{|c|c|c|c|c|c|c|}
\hline \multirow[b]{3}{*}{ Factors } & \multicolumn{6}{|c|}{ Formulations } \\
\hline & \multicolumn{2}{|c|}{ F9 } & \multicolumn{2}{|c|}{ F10 } & \multicolumn{2}{|c|}{ F19 } \\
\hline & Higuchi & Target & Higuchi & Target & Higuchi & Target \\
\hline$f_{1}$ & 28.0 & 20.0 & 12.7 & 4.4 & 7.5 & 2.7 \\
\hline$f_{2}$ & 36.9 & 45.8 & 53.2 & 74.4 & 64.6 & 82.5 \\
\hline
\end{tabular}

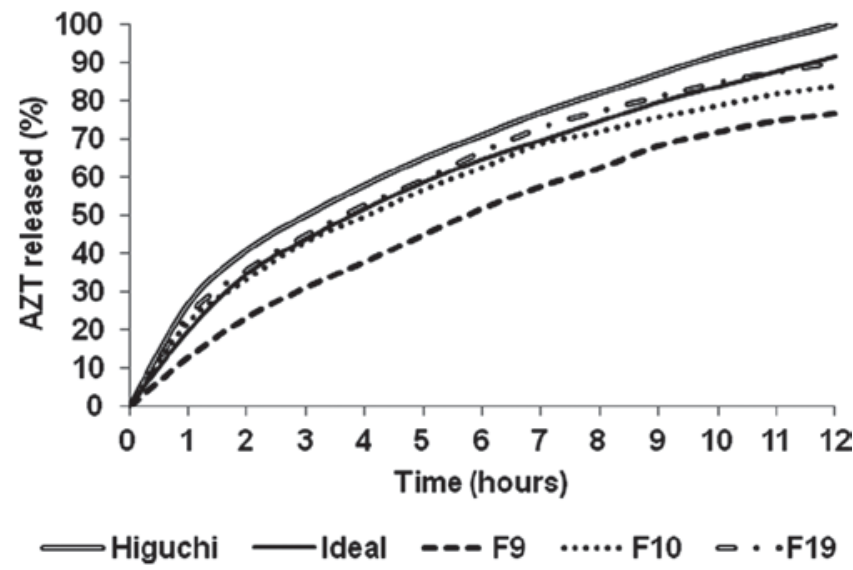

Figure 9. Drug-release profiles for some zidovudine formulations compared with both ideal release profiles (see text). 
comparison purposes). It was verified that exposure of the Caco-2 cells to the distinct formulations F9, F10, and F19, and to AZT alone, led to a marked viability decrease (up to 85\%) according to a time-dependent profile (Figure 10). Also, the matrix formulations displayed a lower cytotoxic effect as compared to the pure drug (no significant statistical difference having been found between these results).

\section{Reversibility of the cytotoxic effect}

The reversibility of the cytotoxic effect of zidovudine and its formulations F9, F10, and F19 against the Caco- 2 cell line was assessed, by the ability of these cells to resume their normal growth process after incubation with the drug.

Upon incubation of the cells with the tested formulations for a 48-h period, the drug-containing medium was replaced by fresh, drug-free medium. The morphological aspect of the culture and the cell viability were then assessed, at different time points $(3,6,9,12$, and $24 \mathrm{~h})$, to evaluate the reversibility of the drug effect (Figure 11). This was found to be lower for formulation F19 (namely after 9, 12, and $24 \mathrm{~h}$ upon drug removal). Pure AZT displays only a slightly lower reversibility relative to these formulations - ca. $10 \%$ for AZT versus $15 \%$ for F19.

The results presently reported evidence of quite a high reversibility of the effect exerted by these AZT formulations against the Caco-2 cell line, according to the order: F9 > F10 > F19. The maximum loss of cell viability measured, that is, the maximum percentage of cells that did not show the ability to reverse the cytotoxic effect of the drug, was found to be $17 \%$, for formulation F19. In fact, while for preparations F9 and F10 this effect was completely reversed after 8 to 10 days of drug removal, for F19 recovery of normal cell growth was only verified after 21 days in the absence of zidovudine (Figure 12).

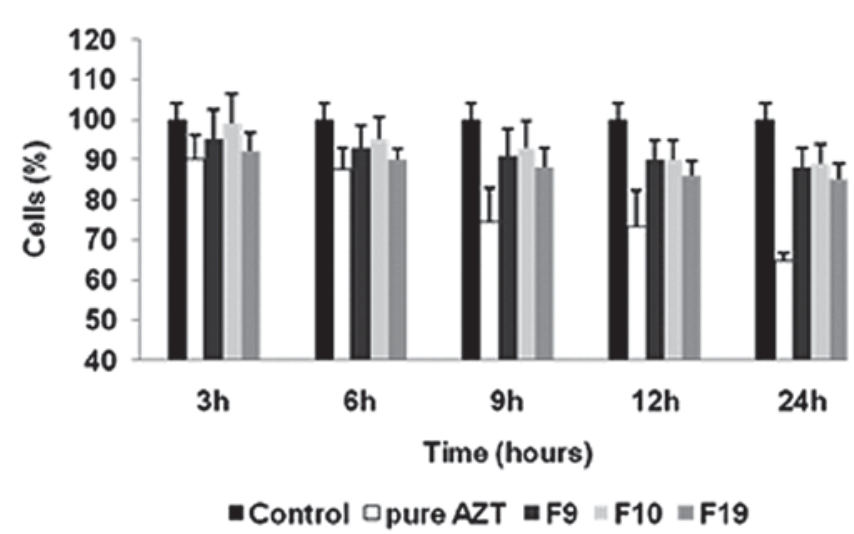

Figure 10. Time dependence of the cytotoxic effect of pure zidovudine and the zidovudine formulations F9, F10, and F19 toward the Caco-2 cell line, for a drug concentration of $100 \mu \mathrm{M}, 92$ $\mu \mathrm{M}, 97 \mu \mathrm{M}$, and $99 \mu \mathrm{M}$, respectively. Cell viability was evaluated by the SRB colorimetric assay (as described in the "Materials and methods"). (The results are expressed as a percentage of the control $(100 \%)$, and represent the mean \pm SD for three independent experiments performed in triplicate; $p=0.53$, $\mathrm{F}=0.80$, with $\mathrm{F}_{\text {critical }}=2.49$.)

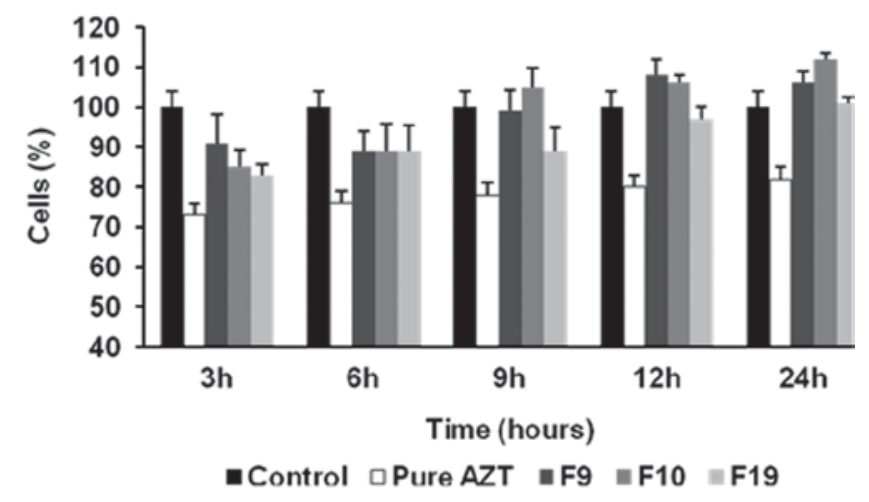

Figure 11. Reversibility of the cytotoxic effect of pure zidovudine and the zidovudine formulations F9, F10, and F19 toward the Caco-2 cell line, for a drug concentration of $100 \mu \mathrm{M}, 92 \mu \mathrm{M}, 97$ $\mu \mathrm{M}$, and $99 \mu \mathrm{M}$, respectively. Cells were washed and fed with fresh media, $48 \mathrm{~h}$ following addition of the drug. Cell viability was evaluated by the SRB colorimetric assay (as described in the "Materials and methods"). (The results represent the mean \pm SD of three independent experiments, performed in triplicate; $p=0.02$ and $\mathrm{F}=3.03$, with $\mathrm{F}_{\text {critical }}=2.54$.)

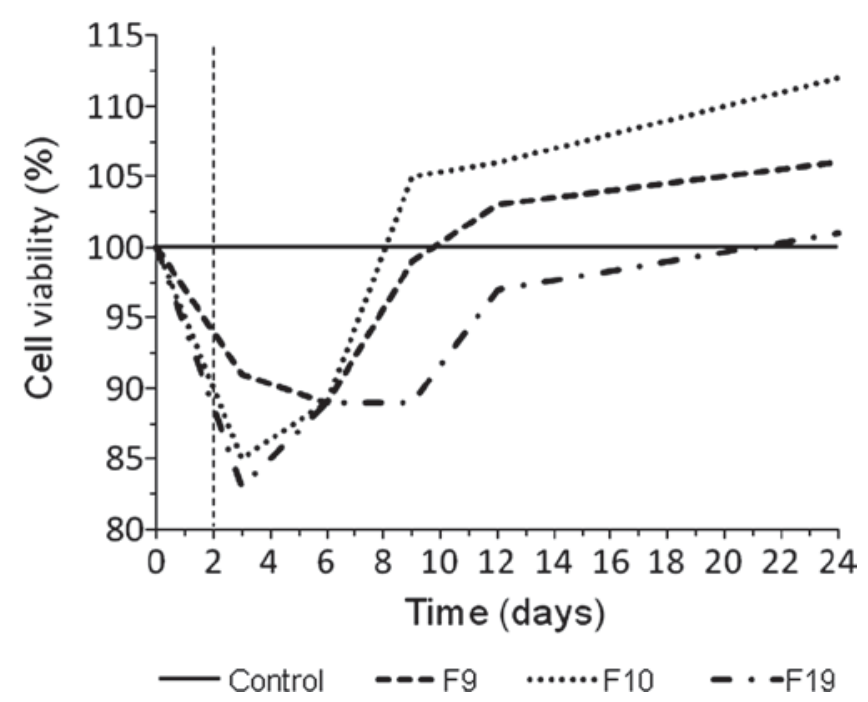

Figure 12. Graphical representation of the reversibility of the cytotoxic effect exerted by pure zidovudine and the zidovudine formulations F9, F10, and F19 toward the Caco-2 cell line, for a drug concentration of $100 \mu \mathrm{M}, 92 \mu \mathrm{M}, 97 \mu \mathrm{M}$, and $99 \mu \mathrm{M}$, respectively. Cell viability was evaluated by the SRB colorimetric assay (as described in the Materials and Methods). The dashed line represents the removal of the drug.

\section{Conclusion}

Although hydrophilic swellable polymers (e.g., HPMC) are widely used to control the release of drugs from solid matrix formulations, they do not comply with the required AZT release profile when used alone. Therefore, it is presently suggested to combine swellable polymers with nonswellable ones, aiming at a modulation of the liberation process according to the desired release profile.

The hydrophobic polymer Eudragit ${ }^{\circledR}$ was tested, since it was verified that it was suitable as a matrix agent and allowed a direct compression preparation, which is both 
simple and economical for industrial uses. All examined formulations yielded tablets with good and reproducible technological properties. The evaluation of the release mechanisms evidenced a non-Fickian (anomalous) transport for all tested formulations. Formulation F19, containing $5 \%$ of each excipient - HPMC K15M, HPMC K100M, Eudragit ${ }^{\circledR}$ RS PO, and Eudragit ${ }^{\circledR}$ RL PO - was found to be the one yielding the best release profile, that is, displaying a higher similarity $f_{2}$ factor relative to the two ideal target profiles considered. Moreover, this formulation is lactose-free, which is particularly important since most of the patients, especially HIV ones, may develop lactose intolerance.

The changes presently observed in the human cancer cell line Caco-2 upon administration of zidovudine, either alone or in polymeric formulations, were determined, regarding cell growth and viability as well as cell morphology. Overall, the presence of the polymers was found to decrease the drug toxicity toward these cancer cells, as compared to pure AZT. Formulation F19 was found to be the most effective toward these cells, causing a viability loss of ca. $15 \%, 24 \mathrm{~h}$ after drug administration. Furthermore, the cytotoxicity screening presently carried out revealed a quite high reversibility of this effect, F19 yielding the less reversible viability loss - 21 days to complete recovery in the absence of drug.

\section{Acknowledgments}

The authors thank IPATIMUP (Institute of Molecular Pathology and Immunology of the University of Porto, Portugal) for kindly making available the human caucasian colon adenocarcinoma cell line Caco-2.

Declaration of Interest: The authors report no conflicts of interest. J.V.S. acknowledges $\mathrm{PhD}$ fellowship from the Programme Alßan, the European Union Programme of High Level Scholarships for Latin America (scholarship no. E06D100103BR).

\section{References}

1. FDA (Food and Drug Administration). 2010. HIV/AIDS Historical Time Line 1981-1990. US Department of Health \& Human Services. Available at: http://www.fda.gov/ForConsumers/ByAudience/ ForPatientAdvocates/HIVandAIDSActivities/ucm 151074. htm\#1988.

2. Fischl MA, Parker CB, Pettinelli C, Wulfsohn M, Hirsch MS, Collier AC, Antoniskis D, Ho M, Richman DD, Fuchs E, Merigan TC, Reichman RC, Gold J, Steigbigel N, Leoung GS, Rasheed S, Tsiatis A. Recombinant human erythropoietin for patients with AIDS treated with zidovudine. N Eng J Med, 1990; 323:1009-1014.

3. Balint GA. (2001). Antiretroviral therapeutic possibilities for human immunodeficiency virus/acquired immunodeficiency syndrome. Pharmacol Ther, 89:17-27.

4. Klecker RW Jr, Collins JM, Yarchoan R, Thomas R, Jenkins JF, Broder S et al. (1987). Plasma and cerebrospinal fluid pharmacokinetics of $3^{\prime}$-azido-3'-deoxythymidine: a novel pyrimidine analog with potential application for the treatment of patients with AIDS and related diseases. Clin Pharmacol Ther, 41:407-412.

5. Dudley MN. (1995). Clinical pharmacokinetics of nucleoside antiretroviral agents. J Infect Dis, 171 Suppl 2:S99-112.

6. Vial T, Descotes J. (1995). Drugs acting on the immune system. Side Eff Drugs Annu, 19:334-368.

7. Friedland G. (2008) HIV medication adherence: the intersection of biomedical, behavioral, and social science research and clinical practice. J Acquir Immune Defic Syndr, 43:3-9.

8. Ojewole E, Mackraj I, Naidoo P, Govender T. (2008). Exploring the use of novel drug delivery systems for antiretroviral drugs. Eur J Pharm Biopharm, 70:697-710.

9. Tajiri S, Kanamaru T, Kamada M, Makoto K, Konno T, Nakagami H. (2010). Dosage form design and in vitro/in vivo evaluation of cevimeline extended-release tablet formulations. Int J Pharm, 383:99-105.

10. ICCVAM (Interagency Coordinating Committee on the Validation of Alternative Methods). Report of the international workshop on in vitro methods for assessing acute systemic toxicity. NIH Publication 01-4499. National Institute of Environmental Health Sciences, Research Triangle Park, NC, USA, 2001. Available at: http://iccvam.niehs.nih.gov/.

11. ICCVAM (Interagency Coordinating Committee on the Validation of Alternative Methods). Guidance document on using in vitro data to estimate in vivo starting doses for acute toxicity. NIH Publication 01-4500. National Institute of Environmental Health Sciences, Research Triangle Park, NC, USA, 2001. Available at: http://iccvam.niehs.nih.gov/.

12. Salama NN, Eddington ND, Fasano A. (2006). Tight junction modulation and its relationship to drug delivery. Adv Drug Deliv Rev, 58:15-28.

13. Li P, Zhao L. (2007). Developing early formulations: practice and perspective. Int J Pharm, 341:1-19.

14. Hansch C, Leo A, Mekapati SB, Kurup A. (2004). QSAR and ADME Bioorg Med Chem, 12:3391-3400.

15. Gan LL, Thakker DR. (1997). Applications of the Caco-2 model in the design and development of orally active drugs: elucidation of biochemical and physical barriers posed by the intestinal epithelium. Adv Drug Deliv Rev, 23:77-98.

16. Guix S, Bosch A, Ribes E, Dora Martínez L, Pintó RM. (2004). Apoptosis in astrovirus-infected CaCo-2 cells. Virology, 319: 249-261.

17. Chaïbi C, Cotte-Laffitte J, Sandré C, Esclatine A, Servin AL, Quéro $\mathrm{AM}$ et al. (2005). Rotavirus induces apoptosis in fully differentiated human intestinal Caco-2 cells. Virology, 332:480-490.

18. Lo YL, Ho CT, Tsai FL. (2008). Inhibit multidrug resistance and induce apoptosis by using glycocholic acid and epirubicin. Eur J Pharm Sci, 35:52-67.

19. Yang Y, Yu LX. Oral drug absorption, evaluation and prediction, In Yang Y, Yu LX, Yihong Q, Yisheng C, Geoff GZZ, Lirong L, William RP (eds), Developing solid oral dosage forms. San Diego, USA: Academic Press, chap. 12, pp 289-308, 2009.

20. Azenha MA, Evangelista R, Martel F, Vasconcelos MT. (2004). Estimation of the human intestinal permeability of butyltin species using the Caco-2 cell line model. Food Chem Toxicol, 42:1431-1442.

21. Ingels F, Deferme S, Destexhe E, Oth M, Van den Mooter G, Augustijns P. (2002). Simulated intestinal fluid as transport medium in the Caco-2 cell culture model. Int J Pharm, 232:183-192.

22. Kawaguchi H, Akazawa Y, Watanabe Y, Takakura Y. (2005). Permeability modulation of human intestinal Caco-2 cell monolayers by interferons. Eur J Pharm Biopharm, 59:45-50.

23. Kapitza SB, Michel BR, van Hoogevest P, Leigh ML, Imanidis G. (2007). Absorption of poorly water soluble drugs subject to apical efflux using phospholipids as solubilizers in the Caco-2 cell model. Eur J Pharm Biopharm, 66:146-158.

24. Biganzoli E, Cavenaghi LA, Rossi R, Brunati MC, Nolli ML. (1999). Use of a Caco-2 cell culture model for the characterization of intestinal absorption of antibiotics. Farmaco, 54:594-599. 
25. Manna C, Galletti P, Maisto G, Cucciolla V, D'Angelo S, Zappia V. (2000). Transport mechanism and metabolism of olive oil hydroxytyrosol in Caco-2 cells. FEBS Lett, 470:341-344.

26. Li F, Hong L, Mau CI, Chan R, Hendricks T, Dvorak C et al. (2006). Transport of levovirin prodrugs in the human intestinal Caco-2 cell line. J Pharm Sci, 95:1318-1325.

27. Artursson P, Neuhoff S, Matsson P, Tavelin S. Passive permeability and active transport models for the prediction of oral absorption, In: Testa B, van de Waterbeemd $\mathrm{H}$ (eds), Comprehensive medicinal chemistry II., Oxford: Elsevier, chap 5.11, pp 259-278, 2007.

28. Kobayashi S, Tanabe S, Sugiyama M, Konishi Y. (2008). Transepithelial transport of hesperetin and hesperidin in intestinal Caco-2 cell monolayers. Biochim Biophys Acta, 1778:33-41.

29. Katragadda S, Jain R, Kwatra D, Hariharan S, Mitra AK. (2008). Pharmacokinetics of amino acid ester prodrugs of acyclovir after oral administration: interaction with the transporters on Caco-2 cells. Int J Pharm, 362:93-101.

30. Nagy EA, Bajpai PK. (1994). Development of a ceramic matrix system for continuous delivery of azidothymidine. Biomed Sci Instrum, 30:181-186.

31. Mandal TK, Lopez-Anaya A, Onyebueke E, Shekleton M. (1996). Preparation ofbiodegradable microcapsules containingzidovudine (AZT) using solvent evaporation technique. J Microencapsul, 13:257-267.

32. Abu-Izza KA, Garcia-Contreras L, Lu DR. (1996). Preparation and evaluation of sustained release AZT-loaded microspheres: optimization of the release characteristics using response surface methodology. J Pharm Sci, 85:144-149.

33. Rao KR, Senapati P, Das MK. (2005). Formulation and in vitro evaluation of ethyl cellulose microspheres containing zidovudine. J Microencapsul, 22:863-876.

34. Kuksal A, Tiwary AK, Jain NK, Jain S. (2006). Formulation and in vitro, in vivo evaluation of extended- release matrix tablet of zidovudine: influence of combination of hydrophilic and hydrophobic matrix formers. AAPS PharmSciTech, 7:E1.

35. Jain S, Tiwary AK, Jain NK. (2006). Sustained and targeted delivery of an anti-HIV agent using elastic liposomal formulation: mechanism of action. Curr Drug Deliv, 3:157-166.

36. Ravi PR, Ganga S, Saha RN. (2008). Design and in vitro evaluation of zidovudine oral controlled release tablets prepared using hydroxypropyl methylcellulose. Chem Pharm Bull, 56:518-524.

37. Ravi PR, Kotreka UK, Saha RN. (2008). Controlled release matrix tablets of zidovudine: effect of formulation variables on the in vitro drug release kinetics. AAPS PharmSciTech, 9:302-313.

38. Takmaz EA, Inal O, Baykara T. (2009). Studies on transdermal delivery enhancement of zidovudine. AAPS PharmSciTech, 10: 88-97.

39. Carvalho FC, Sarmento VH, Chiavacci LA, Barbi MS, Gremião MP. (2010). Development and in vitro evaluation of surfactant systems for controlled release of zidovudine. J Pharm Sci, 99:2367-2374.

40. Emeje M, Olaleye O, Isimi C, Fortunak J, Byrn S, Kunle O et al. (2010). Oral sustained release tablets of zidovudine using binary blends of natural and synthetic polymers. Biol Pharm Bull, 33:1561-1567.

41. Ruckmani K, Sankar V. (2010). Formulation and optimization of Zidovudine niosomes. AAPS PharmSciTech, 11:1119-1127.

42. Santos JV, Batista de Carvalho LAE, Pina ME. (2010). The influence of the compression force on zidovudine release from matrix tablets. AAPS PharmSciTech, 11:1442-1448.

43. Santos JV, Batista de Carvalho LAE, Pina ME. (2011). Development and validation of a RP-HPLC method for determination of zidovudine and its related substances in sustained release tablets. Anal Sci, 27:283-289.

44. Costa P, Sousa Lobo JM. (2001). Modeling and comparison of dissolution profiles. Eur J Pharm Sci, 13:123-133.

45. Higuchi T. (1961). Rate of release of medicaments from ointment bases containing drugs in suspension. J Pharm Sci, 50:874-875.
46. Higuchi T. (1963). Mechanism of sustained-action medication. theoretical analysis of rate of release of solid drugs dispersed in solid matrices. J Pharm Sci, 52:1145-1149.

47. Hixson AW, Crowell JH. (1931). Dependence of reaction velocity upon surface and agitation. Ind Eng Chem, 23:923-931.

48. Korsmeyer RW, Gurny R, Doelker EM, Buri P, Peppas NA. (1983). Mechanism of solute release from porous hydrophilic polymers. Int J Pharm, 15:25-35.

49. Khan KA, Rhodes CT. (1972). Effect of compaction pressure on the dissolution efficiency of some direct compression systems. Pharm Acta Helv, 47:594-607.

50. Khan KA. (1975). The concept of dissolution efficiency. J Pharm Pharmacol, 27:48-49.

51. Moore JW, Flanner HH. Mathematical comparison of dissolution profiles. Pharm Tech 1996;20:64-74.

52. FDA, Guidance for Industry: Dissolution testing of Immediate Release Solid Oral Dosage Forms, U.S. Department of Health and Human Services, Food and Drug Administration Center for Drug Evaluation and Research (CDER), US, BP 1, August 1997. Available at: http://www.fda.gov/ cder/guidance/1713bp1.pdf.

53. Shah VP, Tsong Y, Sathe P, Liu JP. (1998). In vitro dissolution profile comparison-statistics and analysis of the similarity factor, f2. Pharm Res, 15:889-896.

54. Costa P. (2001). An alternative method to the evaluation of similarity factor in dissolution testing. Int J Pharm, 220:77-83.

55. Skehan P, Storeng R, Scudiero D, Monks A, McMahon J, Vistica D et al. (1990). New colorimetric cytotoxicity assay for anticancerdrug screening. J Natl Cancer Inst, 82:1107-1112.

56. Keepers YP, Pizao PE, Peters GJ, van Ark-Otte J, Winograd B, Pinedo HM. (1991). Comparison of the sulforhodamine B protein and tetrazolium (MTT) assays for in vitro chemosensitivity testing. Eur J Cancer, 27:897-900.

57. Fricker SP, Buckley RG. (1996). Comparison of two colorimetric assays as cytotoxicity endpoints for an in vitro screen for antitumour agents. Anticancer Res, 16:3755-3760.

58. Papazisis KT, Geromichalos GD, Dimitriadis KA, Kortsaris AH. (1997). Optimization of the sulforhodamine B colorimetric assay. J Immunol Methods, 208:151-158.

59. Lazic MJ, Andelkovic KK, Sladic DM, Tesic ZL, Radulovic SS. (2005). The evaluation of cytotoxic activity of planar pentadentate ligand $2^{\prime}, 2$ '"'-(2,6-pyridindiyldiethylidyne) dioxamohydrazide dihydrate $\left(\mathrm{H}_{2} \mathrm{l} \times 2 \mathrm{H}_{2} \mathrm{O}\right)$ and its metal coordination complexes; pitfalls in the use of the MTT-assay. J Exp Clin Cancer Res, 24:63-68.

60. Marques MPM, Oliveira PJ, Moreno AJM, Batista de Carvalho LAE. (2002). Study of carvedilol by combined Raman spectroscopy and Ab initio MO calculations. J Raman Spectrosc, 33:778-783.

61. Vueba ML, Pina ME, Veiga F, Sousa JJ, de Carvalho LA. (2006). Conformational study of ketoprofen by combined DFT calculations and Raman spectroscopy. Int J Pharm, 307:56-65.

62. Batista de Carvalho LAE, Marques MPM, Tomkinson J. (2006). Drug-excipient interactions in ketoprofen - a vibrational study. Biopolymers, 82:420-424.

63. Vueba ML, Pina ME, Batista de Carvalho LA. (2008). Conformational stability of ibuprofen: assessed by DFT calculations and optical vibrational spectroscopy. J Pharm Sci, 97:845-859.

64. Vueba ML, Batista de Carvalho LA, Veiga F, Sousa JJ, Pina ME. (2004). Influence of cellulose ether polymers on ketoprofen release from hydrophilic matrix tablets. Eur J Pharm Biopharm, 58:51-59.

65. Vueba ML, Batista de Carvalho LA, Veiga F, Sousa JJ, Pina ME. (2005). Role of cellulose ether polymers on ibuprofen release from matrix tablets. Drug Dev Ind Pharm, 31:653-665.

66. Vueba ML, Batista de Carvalho LA, Veiga F, Sousa JJ, Pina ME. (2006). Influence of cellulose ether mixtures on ibuprofen release: MC25, HPC and HPMC K100M. Pharm Dev Technol, 11: 213-228.

67. Desai J, Alexander K, Riga A. (2006). Characterization of polymeric dispersions of dimenhydrinate in ethyl cellulose for controlled release. Int J Pharm, 308:115-123. 
68. Duarte AR, Costa MS, Simplício AL, Cardoso MM, Duarte CM. (2006). Preparation of controlled release microspheres using supercritical fluid technology for delivery of anti-inflammatory drugs. Int J Pharm, 308:168-174.

69. Ford JL, Rubinstein MH, McCaul F, Hogan JE, Edgar PJ. (1987). Importance of drug type, tablet shape and added diluents on drug release kinetics from hydroxypropylmethylcellulose matrix tablets. Int J Pharm, 40:223-234.

70. Conti S, Maggi L, Segale L, Ochoa Machiste E, Conte U, Grenier P et al. (2007). Matrices containing NaCMC and HPMC 1. Dissolution performance characterization. Int J Pharm, 333: 136-142.

71. Peppas NA. (1985). Analysis of Fickian and non-Fickian drug release from polymers. Pharm Acta Helv, 60:110-111.

72. Zuleger S, Lippold BC. (2001). Polymer particle erosion controlling drug release. I. Factors influencing drug release and characterization of the release mechanism. Int J Pharm, 217:139-152.

73. European Medicines Agency. Note for guidance on Quality of modified release products: A: oral dosage forms; B: transdermal dosage forms, CPMP/QWP/604/96. London, 1999.

74. European Medicines Agency, Note for guiance specifications: test procedures and acceptance criteria for new drug substances and new drug products: Chemical substances. CPMP/ICH/367/96. London, 2000.

75. Cohen JL, Hubert BB, Leeson LJ, Rhodes CT, Robinson JR, Roseman TJ et al. (1990). The development of USP dissolution and drug release standards. Pharm Res, 7:983-987.

76. Prista LN, Alves AC, Morgado RMR, Sousa Lobo JM. Formas farmacêuticas de disponibilidade modificada, In: Prista LN, Alves AC, Morgado RMR, Sousa Lobo JM (eds), Tecnologia Farmacêutica. Lisbon: Fundação Calouste Gulbenkian. pp 2025-2054, 2008. 